\title{
A MÚSICA EM SCHELLING E O RITMO UNIVERSAL DO ABSOLUTO
}

\author{
Evelyn G. Petersen de Barros ${ }^{1}$ \\ Universidade Federal do Paraná (UFPR)
}

\begin{abstract}
RESUMO:
O presente artigo visa problematizar a concepção de música proposta pelo filósofo Friedrich Schelling em sua obra 'Filosofia da Arte', na qual essa forma artística é concebida enquanto uma potência (Potenz) real do Absoluto. Desse modo, pretendese apontar para o caráter inovador e peculiar da concepção schelliniana em contraste com a noção romântica de música absoluta, assim como situá-la dentro do panorama geral do sistema de identidades desenvolvido pelo autor.
\end{abstract}

PALAVRAS-CHAVE: Schelling; Filosofia da música; Filosofia da arte; Ritmo; Idealismo alemão.

\section{MUSIC AND THE UNIVERSAL RHYTHM OF ABSOLUTE IN SCHELLING'S WORK}

\begin{abstract}
:
This article aims to discuss the musical conception proposed by German philosopher Friedrich Schelling in his work 'Philosophy of Art', which conceives music as a real potency (Potenz) of Absolute. Therefore, we intent to underlie the peculiar and original aspects of Schelling's ideas as they are demonstrated by his philosophical system of identities, in contrast with the romantic notion of absolute music.
\end{abstract}

KEY WORDS: Schelling, Philosophy of music; Philosophy of art; German idealism.

Filosofia e arte

Talvez - disse Kretzschmar - seja o mais íntimo desejo da Música não ser ouvida, nem tampouco ser vista ou sentida, e sim, se possível, ser percebida e enxergada unicamente num além dos sentidos e até da alma, numa região espiritualmente pura. (MANN, 1947, p. 84).

\footnotetext{
${ }^{1}$ Mestranda em Filosofia pela Universidade Federal do Paraná (UFPR), Paraná - Brasil.
} 
A sugestão contida na observação da personagem de Thomas Mann de que a música deve ser percebida 'num além dos sentidos' indica a existência de um domínio intocado, anterior à finitude divisora, que nos é descortinado por meio da contemplação estética. E nada poderia ser mais schelliniano do que a atitude de imputar à intuição estética o vislumbre do próprio Absoluto encarnado em seus produtos artísticos. A referência 'ao mais íntimo desejo da música', como se conferisse a ela uma autoconsciência, também nos remete à concepção schelliniana de um Absoluto não-estático, que, perpassado por uma força dinâmica, é impelido a sair de si próprio pelo anseio em tornar-se autoconsciente.

O sistema de filosofia desenvolvido por Schelling será baseado na ideia de um primeiro princípio autossuficiente e absoluto $^{2}$, que fundamenta toda a realidade e todo o conhecimento: a mesma força dinâmica presente nos atos do espírito será encontrada na produção da natureza, ou seja, a natureza e o espírito, embora apareçam separados para o sujeito, irão pressupor sempre um mesmo fundamento comum. Tal primeiro princípio, em Schelling, não deve ser compreendido como uma proposição suprema, originária e estática, que em algum momento no tempo dá origem a uma sucessão de proposições subsequentes. Ao contrário, a unidade originária de Schelling é aquela que comporta, a um só tempo, a intenção em direção à multiplicidade, necessária para o aparecimento do Absoluto, e cujo resultado final - definido pelo reconhecimento da identidade pelo sujeito - coincide com o princípio, de modo que "a natureza deverá ser o espírito visível, e o espírito, natureza invisível" ${ }^{3 ”}$ (SCHELLING, 1907, p. 55) ${ }^{4}$.

\footnotetext{
${ }^{2}$ A fissura decorrente da passagem do Absoluto para a finitude, que num momento posterior Schelling chamará de "queda" (Abfall), resultará em um elemento objetivo e inconsciente e em outro subjetivo e consciente. A filosofia da natureza, que representa o aspecto objetivo da cisão, terá por tarefa demonstrar o processo crescente de "espiritualização" da natureza, desde os seus mecanismos mais simples até sua culminância numa completa estrutura orgânica, coincidente com o aparecimento da consciência. O idealismo transcendental, por sua vez, partindo do surgimento da consciência, procura demonstrar o processo de objetivação do espírito através de sua atividade teórica, do exercício da liberdade prática, e, finalmente através dos seus produtos artísticos, que permitem ao sujeito contemplar o seu fundamento originário.

3 "Die Natur soll die sichtbare Geist, der Geist die unsichtabare Natur sein."
} 
Em O sistema do idealismo transcendental, Schelling fornece sua primeira concepção sistemática e fundamental acerca da relação entre arte e filosofia. Nesta obra, o filósofo pretende perfazer a 'história da autoconsciência', a qual, partindo da produção das categorias teóricas pelo sujeito, culmina com a consideração da arte como o verdadeiro organon da filosofia, por restaurar para o próprio sujeito, sob a forma finita do objeto, a unidade perdida entre natureza e espírito, sujeito e objeto. Sobre o papel da arte diz Schelling:

Se a intuição estética é somente a intuição transcendental tornada objetiva, é evidente que a arte, a um só tempo, é o único documento e órgão verdadeiro e eterno da filosofia, o qual tem atestado desde sempre, o que a filosofia não pode apresentar externamente, a saber, o inconsciente em sua ação e produção, assim como sua identidade originária com o consciente. Por isso mesmo a arte é o que há de mais elevado para o filósofo, porque lhe abre, por assim dizer, o santuário onde arde em uma única chama, em eterna e originária união, o que está separado na natureza e na historia, e que na vida e na ação, assim como no pensamento, há de escapar eternamente [...]. O que chamamos de natureza é um poema cifrado em maravilhosos caracteres ocultos. (SCHELLING, 1907, p.301-302) ${ }^{5}$.

A filosofia teórica não pode representar positivamente o absoluto, pois o pensamento reflexivo opera a partir da posição onde a identidade originária já foi perdida, no momento da emergência da consciência. Ou seja, o Absoluto, como tal, torna-se fundamento do ser, mas não do saber teórico. A unidade desde sempre interditada à reflexão teórica, que "faz o mundo real desaparecer totalmente diante de nós” (SCHELLING, 1985, p. 622), será desvelada na última seção do Sistema, dedicada à teleologia e à arte, na qual se descobre a união entre natureza e liberdade. O filósofo transcendental é capaz de reconhecer a identidade original da atividade consciente e inconsciente da natureza, como aquela atividade cujo fim é a formação da própria consciência, que imediatamente divide a unidade em termos opostos. Apesar disso, o fundamento último sobre o qual repousa a unidade entre sujeito e objeto permanece inacessível a ele enquanto sujeito (sich selbst). O único modo através do qual esse fundamento se torna objetificável ao sujeito é a intuição da arte, que é a intuição intelectual tornada objetiva:

\footnotetext{
${ }^{4}$ As citações referentes a Bowie, Biddle, Hoffman e à edição das obras completas de Schelling (WERKE, LEIPZIG, 1907), foram traduzidas pela autora.

5 "Wenn die ästhetische Anschauung nur die objektiv gewordene transzendentale ist, so versteht sich von selbst, daß die Kunst das einzige wahre und ewige Organon zugleich und Dokument der Philosophie sei, welches immer und fortwährend aufs neue beurkundet, was die Philosophie äußerlich nicht darstellen kann, nämlich das Bewußtlose im Handeln und Produzieren und seine ursprüngliche Identität mit dem Bewußten. Die Kunst ist eben deswegen dem Philosophen das Höchste, weil sie ihm das Allerheiligste gleichsam öffnet, wo in ewiger und ursprünglicher Vereinigung gleichsam in Einer Flamme brennt, was in der Natur und Geschichte gesondert ist, und was im Leben und Handeln, ebenso wie im Denken, ewig sich fliehen muß. Was wir Natur nennen, ist ein Gedicht, das in geheimer wunderbarer Schrift verschlossen liegt.“
} 


\begin{abstract}
A intuição que postulamos une aquilo que existe separado na aparência de liberdade e a intuição do produto natural; nomeadamente a identidade da consciência e inconsciência no eu, e a consciência desta identidade (SCHELLING, 1907, p. 313).
\end{abstract}

Somente ela pode articular, de forma satisfatória, aquilo que não foi levado ao seu ponto culminante: a) pela natureza, em função da privação de consciência da identidade que é a ela essencial; b) pela razão teórica, incompetente para tornar objetivo o vínculo essencial entre produção e produto; e finalmente, c) pela razão prática, não permitindo, na ação livre, a identidade entre consciente e não-consciente, subjetivo e objetivo, já que ela aboliria o objeto da ação livre, a saber, "um objeto infinito, nunca completamente realizado" (VIEIRA, 2007, p. 37-38).

Compreendendo a existência de uma profunda relação entre arte e natureza, Schelling creditará à produção do objeto artístico uma força inconsciente, plasmada à intenção livre do artista. Durante o processo de produção, que parecerá inteiramente consciente, poder-se-á observar a presença de elementos jamais pré-fixados pelo artista, na medida em que o produto artístico objetiva-se, como se seguisse à leis próprias que fogem ao domínio do próprio artista enquanto tal. Assim como a natureza parte da atividade inconsciente para chegar à consciente, a obra de arte começa de forma consciente e termina de forma inconsciente, sendo o produto não o resultado da atividade livre e intencional do artista, mas de sua fusão com a atividade inconsciente que é independente da liberdade. Deste modo,

Schelling buscará recuperar o elemento perdido da natureza, do inconsciente, sem sair totalmente de dentro do próprio domínio especulativo, pois a coincidência entre a atividade inconsciente da natureza, e da atividade consciente do sujeito precisa ser reconhecida pelo próprio sujeito através do órgão artístico.

\title{
Filosofia e música
}

As considerações de Schelling sobre a arte musical, desenvolvidas em sua obra Filosofia da Arte (1803) coincidem com a mudança de perspectiva operada pelo ideário romântico, que elevara a música a um grau de importância inédito dentro da hierarquia das formas artísticas. No breve período que separa as concepções estéticas de Kant e Hoffmann concernentes à arte musical pode-se observar uma notável reviravolta: antes considerada uma manifestação artística inferior, a música torna-se o veículo por excelência de um modo privilegiado de conhecimento do mundo.

Um dos fatores que propiciaram a revolução estética e os novos rumos da reflexão musical no final do século dezoito e início do século dezenove foi o desenvolvimento e a expansão da música instrumental. Em A Crítica do Juízo (1790), Kant assinala a capacidade que a música instrumental tem de atingir os sentimentos dos ouvintes (mehr Genuss als Kultur), sendo considerada inferior à música vocal pelo fato de não informar nenhum conceito à razão.

Ao reivindicar que o juízo de gosto poderia ser baseado nos sentimentos e ainda assim ser dotado de validade universal, ele se contrapõe à tradição estética setecentista de cunho empiricista (Hume, Hutcheson, Burke) e racionalista 
(Baumgarten, Meier), que ou considerava o juízo sobre o belo uma expressão dos sentimentos destituída de conteúdo cognitivo, ou como um conhecimento racional de um objeto dotado de propriedades objetivas. Seu esforço consistia em mostrar que os juízos de gosto são dotados de princípios a priori, tal como nas críticas precedentes, possuindo um papel regulativo para a experiência.

O papel inferior atribuído à música na Crítica do Juízo está relacionado a uma hierarquia das belas artes baseada num critério 'extra-artístico', que toma como fundamento a ampliação das faculdades ${ }^{6}$ que, no juízo, têm o papel de se reunir para o conhecimento:

Se contrariamente se apreciar o valor das belas-artes segundo a cultura que elas alcançam para o ânimo e tomarmos como padrão de medida o alargamento das faculdades que na faculdade do juízo têm de concorrer para o conhecimento, então a música possui entre as artes belas o último lugar (assim como talvez o primeiro entre aquelas que são apreciadas simultaneamente segundo o seu agrado), porque ela joga simplesmente com sensações. (KANT, 1997 p.79).

Irá nos interessar, portanto, a distinção operada por Kant entre os juízos reflexivos associados à sensação do agradável e ao juízo sobre o belo, associado à produção dos objetos artísticos. Trata-se, este último, de um juízo desinteressado, referindo-se a um fundamento subjetivo, pelo aspecto da sensibilidade. O agradável, por sua vez, sendo dotado de interesse, não possui validade universal, podendo ser expresso simplesmente pelo fato de alguém se "agradar" de algo, restringindo-se a ser uma 'mola propulsora de apetites', que, além não cultivar o gosto, extingue-se rapidamente. Ao classificar a música na categoria das artes do belo jogo das sensações (Spiel der Empfindungen), Kant demonstra uma tendência a defini-la como uma arte que envolve meramente impressões sensíveis ${ }^{7}$. Nesse sentido, Kant filia-se, em partes, à corrente estética predominante da época que considerava a música instrumental incapaz de veicular qualquer tipo de significado ao ouvinte.

O antagonismo a este modo de reflexão não tardou a despontar nos primeiros anos do alvorecer da filosofia romântica e idealista, quando surge pela primeira vez a ideia de música absoluta ${ }^{8}$. A música instrumental se torna independente do texto, na medida em que a linha melódica perceptível dá lugar ao "reduzido eco das harmonias" (ROSEN, 2000, p. 10), e o plano composicional na música vocal passa a se assemelhar à técnicas instrumentais. Um momento representativo desta mudança

\footnotetext{
${ }^{6}$ Ou seja, no livre jogo entre imaginação e entendimento.

${ }^{7}$ De acordo com Parret, Kant não leva em consideração a divisão temporal em seu juízo estético sobre a música: "é como se a experiência musical espacializasse automaticamente o tempo musical, de modo que, desde o princípio, Kant iguala a forma no jogo das sensações com a forma espacial" (PARRET, 1998, p. 257).

${ }^{8}$ O termo "música absoluta" apareceu primeiramente nos escritos de filósofos românticos como J.L Tieck, Herder, Wackenroder, Jean Paul (Richter) e Hoffmann. Conforme Scruton, o ideal de pureza requerido pela música absoluta tem sido definido negativamente, como uma forma musical não subordinada às palavras (Lied), ao drama (ópera), a algum sentido representacional (como na música de programa), ou mesmo às vagas exigências da expressão emocional. (Cf. SCRUTON, 1987, p. 37).
}

A música em Schelling e o ritmo universal do absoluto - Evelyn G. Petersen de Barros.

Griot - Revista de Filosofia, Amargosa, Bahia - Brasil, v.4, n.2, dezembro/2011. 48 
acontece apenas duas décadas depois de A Crítica do Juízo: Hoffmann publica, em 1810, uma sucessão de escritos sobre crítica musical (Schriften zur Musik), dentre os quais destaca-se sua famosa crítica à Quinta Sinfonia de Beethoven, na qual louva a música instrumental como sendo a forma musical mais elevada, a única a descortinar ao ouvinte o 'reino do infinito':

\begin{abstract}
Quando se fala da música como arte autônoma, a menção à música instrumental deveria sempre ser feita, a qual, desprezando toda ajuda e toda mistura de outra arte, exprime a essência da arte de maneira pura, sendo que tal peculiaridade só pode nela ser identificada. Ela é a mais romântica das artes - por assim dizer - a única verdadeiramente romântica. (HOFFMAN, 1971, p. 34). ${ }^{9}$
\end{abstract}

Se outrora era o caráter não-conceitual da música o que a fazia um gênero menor, será justamente essa característica que levará diversos autores a considerarem-na a forma artística mais apta a exprimir o inefável. Segundo Rose, ao fim do século dezoito a música passou, gradativamente, a ser considerada uma arte autônoma, visto que a noção de arte enquanto imitação da natureza tornava-se cada vez mais inadequada - haja vista no caráter inovador crescente de sua linguagem.

A problemática do sujeito infinito kantiano é desdobrada pelos românticos no medium da arte e da poesia, num espaço de "intensa reflexão da obra ausente, desejada ou por vir" (BERMAN, 2002, p. 128), que não é filosófico e, tampouco, o da simples criação poética, mas uma combinação de ambos. $\mathrm{O}$ espaço da especulação romântica movimenta-se dentro do ideal da poesia universal (Universalpoesie) de Schlegel, em que se pretende uma fusão da totalidade dos gêneros e formas poéticas, a qual consiste num tipo de reflexão sincrética cuja operação é incessante e infinitizante. Para Schlegel e Novalis, a linguagem depende inteiramente da poesia, pois somente através dela a linguagem atinge uma 'significação pura', o nível de uma linguagem universal, afastada de seu sentido 'natural' e 'comum'.

A autonomização da linguagem musical e a dissolução de seu vínculo espúrio com relação à 'arte da palavra', acompanha a nova concepção romântica da linguagem. Seja pela via místico-especulativa de Schlegel e Novalis, ou pelo modo científico-objetivo de Humboldt e Schleiermacher, a linguagem deixa de ser considerada como mera intermediária entre a realidade significativa e a comunicação, adquirindo o caráter de linguageiro (Sprachlichkeit) ${ }^{10}$, ou seja, por

\footnotetext{
9 “Wenn von der Musik als einer selbständigen Kunst die Rede ist, sollte immer nur die Instrumentalmusik gemeint sein, welche, jede Hilfe, jede Beimischung einer andern Kunst verschmähend, das eigentümliche, nur ihr zu erkennende Wesen der Kunst rein ausspricht. Sie ist die romantischste aller Künste, beinahe möchte man sagen, allein echt romantisch.”

${ }^{10}$ Diz Gamader, em Verdade e Método: "Devemos ao Romantismo alemão o fato de ter antecipado a significação sistemática que possui o caráter linguageiro (Sprachlichkeit) da conversação em relação a qualquer ato de compreender. Ele nos ensinou que compreender e interpretar são, no final das contas, uma única e mesma coisa." (GADAMER, 2008, p.273).
}

A música em Schelling e o ritmo universal do absoluto - Evelyn G. Petersen de Barros.

Griot - Revista de Filosofia, Amargosa, Bahia - Brasil, v.4, n.2, dezembro/2011. 49 
linguagem não mais se considera a representação de um conteúdo universal subjacente, mas o próprio fator constitutivo da compreensão.

Segundo Andrew Bowie, os proponentes do primeiro Romantismo (Frühromantik) (Novalis, Schlegel, Schelling, Scheleiermacher) compartilham a opinião de que a música está associada a um sentido não acessível à articulação conceitual:

$\mathrm{Na}$ filosofia do primeiro romantismo alemão, a comunicação e a compreensão frequentemente são consideradas mais como meios de agir e ser no mundo do que formas de representação de uma realidade previamente dada. A música torna-se particularmente significante, pois mesmo envolvendo uma interpretação baseada em normas, tanto da parte dos músicos quanto dos ouvintes, ainda assim é capaz de resistir à total incorporação no discurso teórico e representacional. (BOWIE, 2007, p.154). ${ }^{11}$

A linguagem é assim associada à música na medida em que não está totalmente sob o domínio do sujeito. A observação de Ritter, de que "os tons são criaturas que se entendem mutuamente" (ROSEN, 2000, p. 116) é semelhante à de Schlegel, quando afirma que "as palavras, com frequência, se entendem mutuamente melhor do que as pessoas que as usam" (ROSEN, 2000, p. 116).

Ao buscar possibilidades ilimitadas de relacionar aspectos do mundo de várias novas maneiras, Novalis, por exemplo, considera a música o símbolo de unidade criada a partir de uma diferenciação cada vez maior. Para Schlegel, a música era acima de tudo, o desejo de se alcançar algo inacessível. A linguagem envolve tipos de inteligibilidade que não podem ser reduzidos ao que a própria linguagem pode explicar, resistindo à total objetificação. É esta resistência a ser considerada como pertencente ao polo do sujeito ou do objeto que abrirá, de acordo com Bowie, a conexão para a música dos românticos.

Em certo sentido podemos dizer que o pensamento de Schelling sobre a música compartilha da convicção romântica acerca da existência de uma origem comum, subjacente à diversidade ilimitada dos fenômenos, e de uma concepção organicista de arte que impõe limites à subjetividade e abre espaço à uma espécie de mística cósmica. Por outro lado, conforme veremos, o lugar que a música ocupa na obra do filósofo apresenta características peculiares, representando, dentro de seu sistema de identidade, uma potência do absoluto.

Conforme já postulado no Sistema do Idealismo Transcendental, a intuição intelectual tornada objetiva no produto artístico é o que permite a compreensão do Absoluto. Seguindo a mesma metodologia do Sistema, que encerra com a dedução transcendental dos produtos de arte, a Filosofia da arte, cuja tarefa Schelling anuncia

\footnotetext{
11 “In early German Romantic philosophy communication and understanding are often regarded more as ways of acting and being in the world than as forms of representation of a pre-given reality. Music becomes particularly significant because it involves norm-based interpretation, on the part both of players and of listeners, and yet resists wholesale incorporation into representational and theoretical discourse. The question is what this means for philosophy".
}

A música em Schelling e o ritmo universal do absoluto - Evelyn G. Petersen de Barros.

Griot - Revista de Filosofia, Amargosa, Bahia - Brasil, v.4, n.2, dezembro/2011. 50 
como sendo a de "expor no ideal o real que existe na arte" (SCHELLING, 2001, p. 27), também constituirá o corolário de seu sistema de identidade.

Embora se mantenha a ideia da arte como elemento unificador entre sujeito e objeto, ao igualar a verdade à beleza na Filosofia da Arte, Schelling alçará a filosofia a um grau tão elevado quanto aquele conferido à arte, pois o filosofo encontra-se na posição de entender o artista melhor do que este a si próprio.

Para o filósofo é mediante a ciência e, em particular, a filosofia que se pode cultivar a capacidade para apreender a Ideia, ou o todo, através das referências recíprocas de suas partes. Fica interditada, portanto, a noção de filosofias ou belezas particulares, pois cada parte do sistema contém, em si mesma, o Todo, sendo por si absolutas. O filósofo chamará de potências a tais formas distintas de determinação da unidade originária, da qual constituem modalidades de exposição. Ou seja, a partir do Absoluto, ou Identidade, (que também será definida enquanto indiferença dos polos opostos) emergem os produtos particulares da natureza e do espírito, revelados como potências no mundo real e ideal, os quais, a despeito de sua oposição, são idênticos. Conforme Schueller,

Ao ser abordado o Absoluto enquanto Absoluto, ele é identidade que nega a diferença. Abordado na forma de uma de suas potências, o absoluto torna-se uma série dinâmica de tensões nas quais realidade e idealidade retornam à identidade somente depois de terem sido submetidas à diferenciação e divisão (SCHUELLER, 1957, p. 465).

O Absoluto, portanto, irá informar (einbilden) a si próprio em cada potência, seja uma potência do espírito, da natureza, ou da arte, as quais corresponderão, respectivamente, às formas de exposição esquemática, alegórica e simbólica. ${ }^{12}$ A força dinâmica na natureza corresponde à atividade criativa do Absoluto, enquanto o espírito investiga o mundo ideal em três potências: filosofia (verdade), liberdade (ética), e arte. As construções da filosofia da arte lidam as com as potências em particular desta formação-em-um (Einbildung) nos produtos artísticos (uma vez que a arte corresponde à filosofia, e assim como ela, percorre todas as potências), os quais são quantitativamente separados em duas séries com três potências cada: à série real corresponde a filosofia da natureza, à serie ideal, a filosofia do espírito.

A arte, tal como a filosofia, está incumbida de expor o protótipo do Absoluto em seus produtos, tornando-o objetivo, ao expor o mundo intelectual no próprio mundo refletido. Como exemplo, Schelling menciona a música como forma artística através da qual o ritmo prototípico da natureza e do universo irrompe no mundo: a música será colocada dentro da série real, correspondente às artes plásticas (bildene

\footnotetext{
12 “Aquela exposição na qual o universal significa o particular, ou na qual o particular é intuído por meio do universal, é esquematismo. Aquela exposição, porém, na qual o particular significa o universal, ou na qual o universal é intuído por meio do particular, é alegórica. A síntese de ambas, onde nem o universal significa o particular, nem o particular, o universal, mas onde ambos são absolutamente um, é o simbólico." (SCHELLING, 2001, p. 69).
} 
kunst $)^{13}$, junto com a pintura e a escultura, visto que aqui a matéria ou ser é elevado ao símbolo da Ideia, ou seja, o infinito, a Ideia, é informada (einbilden) ao finito.

\section{0 ritmo prototípico: a música}

Reflexo do infinito, as artes elencadas na série real são aquelas cuja materialidade as aproxima de modo mais direto e imediato do Absoluto, lembrando que todas as artes comportam um duplo princípio ontológico/transcendental, sendo que em cada uma delas a ênfase da potência recai mais sobre o real ou sobre o ideal, que correspondem ao lado físico ou espiritual. Conforme Schelling, "a cada uma dessas formas, se estão compreendidas na unidade real ou na ideal, corresponde uma forma particular da arte" (SCHELLING, 2001, p.32). Dentre todas, a música é a que apresenta o nível mais elementar de implantação da multiplicidade na unidade, constituindo-se como a mais 'real' das artes. A princípio pode nos soar desconcertante imputar tal concretude a uma forma artística cuja matéria prima, o som, parece-nos distanciada dessa forma de materialidade física. Entretanto, devemos compreender em que sentido Schelling emprega a noção de 'realidade', sem incorrer ao equívoco de confundi-la com algum critério imitativo que aproximaria a forma 'plástica' da música àquela da 'natureza', num sentido restrito.

Schelling entende a música enquanto um modelo proto-orgânico do cosmos: a música é a abstração da forma pura do universo, modelo das coisas eternas. Ser considerada a mais 'real' das artes significa ter sido afetada pelo exercício da liberdade num grau menor, ou seja, significa um modo mais direto de encarnação do Absoluto em um produto material, apresentando a forma corpórea como de certa forma plasmada à forma abstrata do universo.

O seu ponto de partida sistemático é a materialidade física da sonoridade (Klang), à qual a musica é associada de modo elementar. Dissociada do som (Schall) e do ruído $(\text { Laut })^{14}$, a sonoridade é, enquanto dimensão no tempo e puramente como tal, entendida como uma forma abstrata, como "a indiferença da formação-em-um (Einbildung) do infinito no finito, acolhida puramente como indiferença" (SCHELLING, 2001, p.147). A sonoridade é a própria síntese do real e do ideal, da matéria e da ideia, o ponto de indiferença presente na matéria capaz de torná-la símbolo para a arte. ${ }^{15}$

Assemelhada ao magnetismo como um elemento da filosofia da natureza, a sonoridade - ao contrário do magnetismo, que não possui uma existência fora da

\footnotetext{
${ }^{13}$ A série ideal, por sua vez, corresponderá à arte da palavra, que inclui a lírica, a épica e a dramática.

${ }^{14}$ Schelling entende a sonoridade como sendo a categoria superior que compreende tanto o som quanto o ruído, visto que representa o perfeito equilíbrio de sons simultâneos, apreendidos como continuidade.

${ }^{15}$ Visto que ao final de cada série, cada potência é novamente dividida de modo a acolher em si a essência de outras potências, o resultado da série real, qual seja, a matéria, deve necessariamente incluir um ponto de indiferença entre real e ideal a fim de que possa servir como símbolo da arte. A indiferença, portanto, sendo a identidade de duas antíteses, deve conter tanto a materialidade quando a idealidade.
} 
matéria - é a formação-em-um como indiferença justamente por comportar uma forma abstrata e pura independente da matéria "pois esta é, de um lado viva, - por si - de outro, uma mera dimensão no tempo, mas não no espaço" (SHELLING, 2001, p.147). Ao vincular-se a um corpo material, o magnetismo diferencia-se, mas ao se separar dele torna-se indiferença, e, portanto, sonoridade.

A habilidade de um corpo de produzir sonoridade está vinculada a sua coerência, que liberta a sonoridade numa forma autônoma e livre, favorecendo seu status de indiferença na matéria. Este estado perfeito de coerência posta na consonância dos sons é, justamente, a própria materialidade constitutiva da música, a unidade a partir da qual irá moldar seus traços constitutivos. A sonoridade, portanto, participa a um só tempo da matéria, através da oscilação dos corpos, condição de produção do som, e da forma abstrata, por ser uma dimensão no tempo. Desse modo,

(...) na sonoridade, não ouvimos meramente o som simples, mas uma porção de sons como que nela envolvidos ou que nasceram com ela, e de tal modo, que prevalecem os sons consoantes (...). O ouvido exercitado até mesmo os distingue e, além do uníssono ou do tom fundamental, ouve também sua oitava, a oitava da quinta etc. A multiplicidade, que na coerência como tal está vinculada à unidade, torna-se, portanto, na sonoridade, uma multiplicidade viva, uma multiplicidade afirmante de si mesma (SCHELLING, 2001, p.146).

Entendida, portanto, enquanto porção inorgânica do magnetismo, a sonoridade é a implantação do infinito no finito; entendida enquanto porção orgânica do magnetismo, a sonoridade se torna, ela mesma, ouvido (visto que "o órgão da audição é o magnetismo desenvolvido até sua perfeição orgânica") (Schelling, 2001, p.149), elemento de síntese entre o som e/ou a sonoridade e a matéria, permitindo que a sonoridade seja percebida. Implícita nessa definição está a própria noção schelliniana de Absoluto enquanto força ativa, da qual os produtos diferenciados dela provenientes jamais se alienam totalmente, pois ao mesmo tempo em que adquirem autonomia continuam a participar da estrutura total da identidade. Conforme Biddle,

E ainda, pelo fato dessa percepção estar, de algum modo, implícita no produto, o mesmo adquire uma espécie de função auto-realizadora. Logicamente, a música é criada para ser ouvida, mas essa suposição é feita no início, e transformada no processo criativo de tal forma que a própria matéria da música, da sonoridade ou do magnetismo essencial exija a percepção (BIDDLE, 1995. p. 191) ${ }^{16}$.

A música, portanto, é dotada de uma significação interna, na qual a sonoridade entendida como fluxo ininterrupto de sons, não aparece como o resultado de uma combinação sonora a qual se tenha verificado empiricamente bem sucedida,

\footnotetext{
${ }^{16}$ And yet, because this perception is somehow implicit in the product, the product itself takes on a kind of self-fulfilling function. Of course, music is created in order to be heard, but this assumption is made at the outset, built into the creative process such that the very material of music, sonority or essential magnetism demands perception.
} 
mas como uma totalidade que possibilita a própria determinação do som distinto. Nos termos de Barros,

(...) nenhum som distinto poderia determinar-se sem ter feito parte, como possibilidade, de um amálgama vazio de diferenciações. É certo que, na sonoridade, não ouvimos só o som simples, mas "uma porção de sons como que nela envolvidos", e todos concorrendo para um concatenado jogo de tensão e afrouxamento; mas é certo ainda que, como potencialidade, a sonoridade indistinta como que antecede essa escuta. (BARROS, 2007, p. 107, grifo nosso).

Mais à frente, Schelling define a sonoridade ainda como a "própria intuição que o corpo tem da alma', determinação através da qual ele perde seu caráter material e é, imediatamente, transformado num principio interno. Ela se alia à temporalidade $^{17}$, necessária a fim de permitir que uma variedade de tons flua dentro de uma unidade de sonoridade. Daí, que a música, por sua forma necessária, é definida enquanto 'sucessão.'

Puramente como tal, a sucessão será compreendida como mera contingência caso não seja mediada pela potência dominante da música, qual seja, o ritmo. Dotado de uma temporalidade imanente que o associa à autoconsciência, sua regularidade (Gleichmass) o liga às forças elementares da natureza. Capaz de dotar a sucessão de significado, conferindo a ela o caráter de necessidade, o ritmo agora não se deixa subordinar pelo tempo, mas o absorve totalmente na própria constituição da sequência rítmica, tornando-se presença imanente na musica. Como podemos notar:

\begin{abstract}
Visto então universalmente, o ritmo é em geral transformação da sucessão em si insignificante numa sucessão significativa. A sucessão, puramente como tal, tem o caráter da contingência. Transformação do contingente da sucessão em necessidade $=$ ritmo, por meio do qual o todo já não é submetido ao tempo, mas o tem em si mesmo. Articulação da música é formação numa série de membros, de maneira que muitos sons juntos novamente constituam um membro que não é contingentemente ou arbitrariamente diferente dos outros (SCHELLING, 2001, p.148).
\end{abstract}

Por meio das divisões rítmicas, os sentimentos invariáveis transmitidos pela unidade inteiramente homogênea da música adquirem diversidade, tendo seu espectro ampliado. Um sistema vai sendo construído, no qual música ganha forma, significação, em níveis crescentes de complexidade rítmica, do ritmo mais simples, o

\footnotetext{
17 Partindo da definição de tempo enquanto "forma universal da formação-em-um do infinito no finito" abstraída de todo real, a música, por se referir a ele de modo indissociável resulta numa “enumeração-de-si" (selbstzählen) (SCHELLING, 2001, p. 150) na alma. Schelling evoca o elemento "inconsciente" contido no caráter temporal da música ao mencionar o dito de Leibniz, sobre a música ser um "arrebatamento da alma inconsciente de seu próprio enumerar". (SCHELLING, 2001, p. 150).
}

A música em Schelling e o ritmo universal do absoluto - Evelyn G. Petersen de Barros.

Griot - Revista de Filosofia, Amargosa, Bahia - Brasil, v.4, n.2, dezembro/2011. 54 
mero pulsar regular, ao mais composto, definido pela cadência ${ }^{18}$, que permite a variação e formação de novas sequências unificadas de som.

É desse modo, enquanto divisão periódica do homogêneo, que o ritmo é considerado a formação-em-um da unidade na multiplicidade, a primeira potência na música à qual os demais estão subordinados (melodia e modulação).

A segunda potência é a modulação, que pretende revelar a identidade na diferença qualitativa entre os tons ou sonoridades. Assim como o ritmo, que por sua forma regular no tempo torna evidente, quantitativamente, a unidade subjacente a ele, a modulação mantém, na diferença qualitativa, a identidade do tom dominante.

Sempre que uma determinada combinação de elementos, se subordinar ao ritmo, como acontece no caso da melodia, esse aparecerá como fator dominante, e, portanto, será definido como sendo a própria música. Nesse sentido, Schelling compreende ritmo e melodia, definida enquanto terceira potência da música, como sendo a mesma coisa. A modulação, por sua vez, ao suprimir a predominância do ritmo, dá origem à harmonia, definida como a subordinação dos três elementos à segunda unidade.

É desse modo que Schelling explica o surgimento de dois gêneros musicais distintos, ainda que absolutos em sua espécie: o gênero rítmico, o qual calcula ter sido predominante entre os antigos, por conta de seu princípio realista e plástico; e o gênero harmônico, predominante entre os modernos. A distinção que Schelling opera entre os antigos e modernos com relação à música, é semelhante àquela exposta na segunda seção acerca da mitologia. $O$ filósofo atribui um princípio realista às criações mitológicas gregas, capazes de comportar uma realidade per si, puramente simbólica, na qual particular e universal não se referem um ao outro, mas são a mesma coisa, à distinção da mitologia cristã alegorizante, em que o particular referese ao universal a ele extrínseco. A partir desta análise da Antiguidade, Schelling estima que a música, entre os antigos, aferrava-se a um principio real, alcançando um tipo de indiferença na finitude e infinitude através da forma concreta, ao passo que a arte moderna, introduzida pelo cristianismo, ao esquecer o elemento de "música na música" do ritmo como elemento primário, tende a buscar o infinito através da harmonia. Isso notamos no seguinte relato:

Sem dúvida, como diz Rousseau, na época em que os cristãos começaram a cantar hinos e salmos nas próprias igrejas, a música já havia perdido quase toda a sua ênfase. Os cristãos a tomaram tal como a encontraram, e ainda lhe roubaram sua maior força, o andamento e o ritmo [....] (SCHELLING, 2001, p. 155).

Creditando um grau maior de organicidade ao ritmo, o filósofo lamentará o fato de que as complexidades harmônicas desenvolvidas na música moderna, em sua tendência a se afastar cada vez mais da tônica, tenham destruído a cadência e a

\footnotetext{
${ }^{18}$ A cadência é definida por Schelling como "uma espécie mais alta de unidade na diversidade (que) pode ser antes de tudo alcançada quando os sons ou batidas individuais não são indicados com a mesma força, mas variando entre o forte e o fraco, conforme uma certa regra". (SCHELLING, 2001, p. 152).
}

A música em Schelling e o ritmo universal do absoluto - Evelyn G. Petersen de Barros.

Griot - Revista de Filosofia, Amargosa, Bahia - Brasil, v.4, n.2, dezembro/2011. 55 
energia da música rítmica antiga, posição que o coloca em evidente contraste com os desenvolvimentos operados na estética musical de sua própria época, evidenciando certo conservadorismo ${ }^{19}$.

A música harmônica, portanto, será vinculada a um ideal regulativo como produto da liberdade - sendo expressão do esforço e da nostalgia - no sentido em que visa "a antecipação da unidade ideal mais elevada" (SCHELLING, 2001, p. 156) através da supressão da sucessão do ritmo, a fim de substituí-lo pela multiplicidade. Coerente com o quadro geral de seu sistema de identidade, Schelling descreverá a música harmônica enquanto alegoria do infinito, definida como o tipo de exposição em que o universal é intuído no particular e que resulta num grau de particularização crescente. A música rítmica, por sua vez, apresenta-se como uma expansão do infinito no finito, permanecendo mais fiel à destinação natural da música enquanto arte na sucessão, e, portanto, considerada uma forma artística mais realista, mais afastada do domínio da ação rumo ao infinito. Conforme Biddle,

Portanto, noções como melodia/harmonia, historicamente fundadas no
grande debate acerca de a música dever aspirar a um tipo de
espiritualidade inarticulada ou, ao contrário, jorrar naturalmente das
entonações naturais de um testemunho humano apaixonado, são produtos
de um modo particular de pensar, de uma configuração epistemológica
específica. Schelling reconhece implicitamente a impossibilidade de
separação dessas noções na cultura da antiguidade, e lamenta seu conflito
absoluto na cultura cristã do sublime e do alegórico. (BIDDLE, 1995,
p.207).

A correspondência que Schelling opera entre ritmo e natureza, em sua oposição à atividade livre da consciência associada à harmonia, remete a uma noção semelhante, também presente em Schlegel, para a qual o ritmo permite uma espécie

\footnotetext{
${ }^{19}$ Biddle sugere que o contexto histórico-geográfico de Schelling teria influenciado seu desdém pelas novidades da música moderna: "This might be explained by the distortive significance musicology places on the Mozart-Haydn-Beethoven canon for this period. Although Haydn and Mozart had composed some fine examples of the mature classical style by 1804, the year Schelling completed Philosophic, the Mozart-Haydn legacy seemed almost to have faded into obscurity. The so-called galant style of such lesser known symphonists as Anton Koz'eluh, Jan Kr'ititel Van'hal, Franz Anton Hoffmeister and Franz Cram seemed in Vienna, for example, to momentarily overshadow the likes of Mozart and Haydn completely. The comparatively successful commercial careers of these gallant composers as compared with Mozart is attested to in Gerber.249 Also at this time, Beethoven had, admittedly, produced his first symphonies including the Eroica which did not receive performance until 1807 in Leipzig. It is extremely difficult to know exactly how much of this music was accessible in Jena and Wirzburg, where Schelling wrote Philosophie. The small town of Jena, in particular, was probably somewhat removed from the mainstream musical culture of the big centres. Similarly, it is unlikely that much if any Beethoven was played in Jena, although chamber recitals are, of course, not out of the question". (BIDDLE, 1995, p. 197).
} 
de repouso no ser diante do infindável movimento do pensamento. Andrew Bowie observa:

\begin{abstract}
A história proposta por Schlegel se baseia na ideia de que as formas mais desenvolvidas de consciência pela humanidade, que levam à filosofia, são baseadas num estado de insatisfação. Neste estado, o potencial do pensamento para a infinitute leva a uma aflição que pode ser amenizada pela ordem rítmica. O prazer da ordem rítmica deriva do modo como a antecipação é preenchida regularmente, ao invés de simplesmente se manifestar como uma ausência de preenchimento gerada pela expansão ilimitada da atividade do pensamento. (BOWIE, 2007. p. 97). ${ }^{20}$
\end{abstract}

Schelling mesmo chega a se referir à diversidade de juízos acerca da primazia da harmonia e da melodia, aludindo à querela entre Rosseau e Rameau:

Rousseau chama a harmonia de uma invenção gótica, bárbara, em compensação, há entusiastas da harmonia que iniciam a datação da verdadeira música somente a partir da invenção do contraponto. (SCHELLING, 2001, p. 158).

Em seguida, Schelling traça uma correspondência entre as forças centrípeta e centrífuga do universo com o ritmo e a harmonia, consideradas as "formas mais puras" do movimento universal, sob os quais flutuam "os corpos celestes":

No sistema planetário, o ritmo é o dominante, seus movimentos são melodia pura; no sistema dos cometas, a harmonia é dominante. Assim como todo o mundo moderno está universalmente submetido à força centrípeta em direção ao universo, à nostalgia do centro, assim também o estão os cometas, cujos movimentos exprimem, por isso, uma mera confusão harmônica, sem ritmo, e assim como, pelo contrário, a vida e o operar dos antigos era, semelhantemente à sua arte, expansiva, centrífuga, isto é, em si mesma absoluta e rítmica, assim também, comparativamente, a força centrífuga - a expansão do infinito no finito - é dominante nos movimentos dos planetas. (SCHELLING, 2001, p. 158).

Exprimindo a forma das coisas eternas sob o signo da particularidade, as formas da música, assim como a formas do ser e da vida dos corpos celestes, enquanto formas das Ideias consideradas pelo lado real, "integram o ritmo que se ouve e a harmonia do próprio universo visível". De modo que, ao trazer à intuição a forma pura dos movimentos celestes, afastadas de todo objeto, Schelling acaba por considerar a música como a "arte que mais se desfaz do corpóreo", a mais universal, pois representa o ritmo cósmico, a unidade da multiplicidade, fazendo-os acessíveis à

\footnotetext{
20 "Schlegel proposes his story on the basis of the idea that humankind's more developed forms of awareness, which lead to philosophy, are based on an unpleasant state, in which thought's potential for boundlessness leads to a terror which can be tempered by rhythmic order. The pleasure of rhythmic order derives from the way in which anticipation is regularly fulfilled, rather than just manifesting itself as a chaotic lack of fulfilment generated by thought's endless expansive activity."
} 
razão através de uma intuição que prescinde de conceitos, por isso mesmo, "uma arte próxima da dissolução na palavra e na razão", ao mesmo tempo em que "é a potência mais baixa" das artes reais. A aproximação dos dois polos contraditórios - matéria em seu estado bruto e pura forma do movimento - é o que resultará numa unidade idêntica, visto que "matéria e forma são um no Absoluto, e, portanto, no princípio da arte." (SCHELLING, 2001, p. 161).

A música, para Schelling, assim como as outras artes descritas dentro da série "real", é capaz de abstrair o elemento ideal da natureza e de descrever concretamente as estruturas do Absoluto, distintamente de uma noção imitativa de arte focada numa estética do sentimento. A oposição entre melodia "ideal" - síntese criada a partir da diferença entre os tons dentro do todo - e harmonia "real" - que divide a homogeneidade da sucessão - é superada num último estágio em que a musica revela a forma básica do movimento do universo e a estrutura pré-material do mundo, os quais constituem a plena encarnação do ideal, ou seja, o infinito, a Idéia, é informada ao finito.

\section{Referências bibliográficas}

BARROS, Fernando de Moraes. "Schelling e a constituição da estética musical”. In. Trans/Form/Ação, São Paulo, 2007. pp 93-114.

BERMAN, A prova do estrangeiro: Bauru. Edusc, 2002.

BIDDLE, Ian D., Autonomy, Ontology and the Ideal: Music Theory and Philosophical Aesthetics in Early Nineteenth-Century German Thought; Newcast upon Tyne, Newcast University library; 1995.

BOWIE, Andrew: Music, Philosophy and Modernity; London, Cambridge; 2007.

BONDS, Evan Mark: Music as though; Princeton, Princeton University Press; 2006.

HOFFMANN, E.T.A: Schriften zur Musik; Darmstadt: Wissenschaftliche Buchgesellschaft, 1971.

KANT, IMMANUEL: Crítica da faculdade de julgar; Tradução de Antonio Marques e Valerio Rohden. Edições Braile, 1997.

KNITTTERMEYER, Hinrich: Schelling und die Romantische Schule; München; ed. Ernst Reinhartdt; 1928.

MANN, Thomas: Doutor Fausto; Tradução Herbert Caro; Nova Fronteira, 1947.

PARRET, Hermann: "Kant on music and the hierarchy of arts", In Journal of Aesthetics and Art Criticism, 1998, pp. 251-264.

ROSEN, Charles: A geração Romântica. São Paulo, Edusp, 2000.

SCHELling, F.W.J: Filosofia da Arte; Tradução Márcio Suzuki. São Paulo; Edusp; 2001.

: Werke. Auswahl in drei Bänden. Editor Otto Weiß, Fritz

Eckardt, Leipzig, 1907. Vol. 2.

SCHUELLER, Herbert: "Schelling's Theory of the metaphysics of music", In The journal of aesthetics and art criticism, 1957, pp. 461-476.

SCRUTON, Roger: The aesthetic understanding: Essays in the philosophy of art and culture, London, ed. Methuen and Co. Ltd, 1987. 
http://www.ufrb.edu.br/griot

VIEIRA, Leonardo Alves: Schelling. Rio de Janeiro, Zahar, 2007. 